\title{
Accuracy in Discriminating Blood Glucose Levels in a Sample of Children with Type 1 Diabetes
}

\author{
José Luis Ybarra Sagarduy and Jesús Gil Roales-Nieto \\ University of Almería
}

\begin{abstract}
The present study explores accuracy in estimating blood glucose levels (BGL) in children with type 1 diabetes and analyzes the kinds of symptoms and cues which they use to estimate their BGL. Forty two children with type 1 diabetes completed a SI/IC-3 scale consisting of 28 items (22 symptoms and 6 feelings), indicating those which they perceived at the time and their intensity. They estimated their BGL and gave reasons for their estimation, before having a blood glucose level analysis performed. The results indicated great variability in the accuracy of estimating BGL. They showed failures in the correct discrimination of symptoms of hypoglycemia as well as the presence of false beliefs regarding indicative symptoms of hyperglycemia, and the absence of symptoms as an indicator for euglycemia, beliefs which provoke different and frequent errors in the estimation of BGL. Correct use of external signs is shown to be related to correct estimations of normal BGL, as well as hypoglycemia and hyperglycemia. We discuss the implications these results could have on designing psychological intervention procedures for diabetics in the form of training programs to discriminate BGL accurately, taking into account these findings and previous studies completed in the same field.
\end{abstract}

Keywords: type 1 diabetes, estimating BGL, symptom discrimination, internal cues, external cues

El presente estudio explora la precisión en la estimación de los niveles de glucosa en sangre (NGS) en niños con diabetes tipo I y analiza el tipo de síntomas o señales en las que se basan para estimar sus NGS. 42 niños con diabetes tipo I completaron una Escala SI/IC-3 compuestas por 28 ítems (22 síntomas y 6 estados de ánimo), señalando las que percibían en ese momento y la intensidad, y estimaron el NGS indicando las razones de su estimación, antes de realizar su análisis de glucosa en sangre. Los resultados indican una gran variabilidad en la precisión en la estimación del NGS, y muestran fallos en la correcta discriminación de los síntomas señales de hipoglucemias, y la presencia de falsas creencias sobre síntomas indicativos de hiperglucemias y sobre la ausencia de síntomas como indicador de normoglucemia, creencias que provocan diferentes y frecuentes errores en la estimación de los NGS. El uso adecuado de las señales externas se muestra relacionado con la estimación correcta de los NGS tanto normales como hipoglucémicos e hiperglucémicos. Se discuten las implicaciones que estos resultados pueden tener para el diseño de procedimientos de intervención psicológica en diabetes en forma de programas de entrenamiento en discriminación de NGS que tengan en cuenta estos hallazgos y los de estudios previos en la misma línea.

Palabras clave: diabetes tipo I, estimación NGS, discriminación síntomas, señales internas, señales externas

Correspondence concerning this article should be addressed to Jesús Gil Roales-Nieto, Facultad de Humanidades y Ciencias de la Educación, Edificio A, Universidad de Almería, 04120 Almería (Spain). E-mail: jlybarra@ual or jgil@ual.

Translation: Jean L. Feuerstein 
Diabetes mellitus is a chronic systemic disease that affects every aspect of the patients' lives. It can develop at any age and requires complex and continuous treatment. The patients' demeanor is of extreme importance because treatment is often self-administered and needs to be modified constantly. This disease represents one of the most common chronic disorders in infancy and adolescence, with a prevalence of approximately 1.7 affected out of 1000 people aged under 20. In Spain, data show that 5 out of every 1000 children between the ages of 1 and 4, and 2 out of every 1000 children between 5 and 14 years of age suffer from Type 1 diabetes. According to these data of incidence and prevalence of diabetes in children, there are more than 18,000 children younger than 15 with Type 1 diabetes, and every year there will be approximately 700 new cases (Beléndez, Ros, \& Bermejo, 1999).

The active and vital role of the patient in controlling the illness, along with the peculiar and complex characteristics of the biobehavioral regulatory mechanism of blood glucose levels distinctive to diabetes (see Gil Roales-Nieto \& Vílchez Joya, 1993), makes the role of mental health essential. Mental health is vital to good metabolic control (the ultimate goal of treatment) and to solving the multiple inconveniences and problems these patients face the moment they are diagnosed, and during the tiring day-to-day routine involved in living with a disease that has such a high psychological demand.

Diabetes is an endocrine and metabolic disease that affects the ability of the pancreas to secrete insulin, the hormone which "allows" glucose to be used by cells. Consequently, glucose cannot be metabolized by cells. Glucose resulting from the breakdown of ingested food remains in the bloodstream without being able to fulfill its energy-providing function, due to the total or partial lack of this hormone.

There are various types of diabetes, but the two most important are insulin- dependant diabetes mellitus, or Type 1 (IDDM), and non-insulin dependent diabetes mellitus, or Type 2 (NIDDM). Although Type 2, or adult-onset diabetes, is also a very serious chronic illness, we will focus on Type 1 diabetes as the subject of our study. This type of diabetes requires the administration of insulin in order for the patient to survive, and in general, is the result of a destructive process involving the cells of the pancreas, which produces insulin (beta cells of the islets of Langerhans), and usually appears early in life. It is considered an autoimmune disease characterized by the progressive destruction of beta cells in the pancreas and the consequent decrease in its ability to produce insulin. This produces severe metabolic deterioration whose principal characteristic is the inability to metabolize glucose and its accumulation of glucose in the bloodstream, which can, inevitably, lead to death if not treated.

Hyperglycemia is defined as an elevation of blood glucose level (BGL) to above normal limits (a maximum level is considered to be $180 \mathrm{mg} / \mathrm{dl}$ ) and that characterizes untreated diabetes. However, as a consequence of imbalances during treatment, another acute complication, with severe psychological impact on the patient, can occur. This complication is hypoglycemia, defined as BGL below $80 \mathrm{mg} / \mathrm{dl}$. Hypoglycemia usually appears abruptly due to hyperinsulinism caused by the imbalance between glucose and available insulin. There are four situations associated with this occurrence: an overdose of insulin, delayed eating or an imbalance of appropriate food intake, an inappropriate level of physical exercise, and alcohol consumption.

Because of the diabetics' comprehensive and complex diet, patients should be trained to manage its various components. A prime clinical characteristic of diabetes is BGL instability, a variable that is automatically regulated in non-diabetics and maintains a narrow fluctuation between approximately 70 and $150 \mathrm{mg} / \mathrm{dl}$. Diabetics can vacillate between very low figures, which, in the short term, can endanger the patient's life and very high figures, which can provoke medium term consequences. This is why diabetic patients must learn to be aware of these sudden changes in BGL and to correct them.

From a psychological perspective, treatment of Type 1 diabetes is a self-monitoring process in which patients must modify their behavior (e.g., insulin administration, diet, exercise, etc.) in order to maintain their BGL within the established normal range (Gil Roales-Nieto, 2000a; Gil Roales-Nieto \& Vílchez Joya, 1993; Gonder-Frederick, Cox, $\&$ Ritterband, 2002). Therefore, diabetic patients may have to vary the dosage and/or type of insulin they inject, maintain or change their diet, and do more or less exercise depending on variations in their BGL, trying to maintain levels within a normal range whenever possible, so as to avoid both hypoglycemia and hyperglycemia. Self-monitoring is only possible if accurate and immediate feedback regarding BGL is available. Given the numerous occasions throughout the day when this information is not available by an objective measure, diabetic patients must adapt to a functional outline called the "gluco-insulin biobehavioral feedback system" (Gil Roales-Nieto, 2000b, 2004), which combines a complex process of making decisions based on objective and subjective assessments of BGL.

Routine self-monitoring of blood glucose (SMBG), performed with patients' samples of capillary blood, is an essential component in the treatment of diabetes that allows patients to know their exact BGL in less than a minute. But even though the majority of patients receive training and instruction in SMBG implementation as part of their treatment, data indicate weak adherence to SMBG (Jones, Remley, \& Engberg, 1996; Karter, Ferrara, Darbinian, Ackerson, \& Selby, 2000). Reasons for the low compliance to $\mathrm{SMBG}$ include high cost and the relative aversion to taking repeated blood samples, or the numerous obstacles that compete with its compliance such as incompatible schedules, long working hours away from home, etc. (de la 
Fuente \& Gil Roales-Nieto, 1994; Luzoro \& Gil RoalesNieto, 1993; Nyomba, Berard, \& Murphy, 2002; Zgibor \& Simmons, 2002). Furthermore, diabetic patients frequently find themselves in situations where it is impossible to perform SMBG, and can only estimate their BGL based on the presence or absence of the symptoms and cues they believe to be associated with BGL variations (technically called internal cues). Estimations are also based on their knowledge of the disease, the value of distinct parameters of the principle aspects of treatment, and the vital events related to BGL variations (e.g., insulin, diet, stress levels, rest-activity habits, etc.), which are technically called external cues (Gil Roales-Nieto, 1988, 1991a, 1991b). In the life of any diabetic patient, it is normal to perform "estimation trials" dozens of times throughout the day, that is, evaluations of BGL consisting of estimations based on internal and external cues. Therefore, it is appropriate to address this complex behavior, studying the variables on which it depends, the processes involved, and to search for intervention procedures that improve and enhance diabetic control.

Various studies out of the accuracy with which adult diabetic patients estimate their BGL based on internal cues or symptoms have been carried, finding a reduced number of clinically precise estimates, that is, those in which patients were close to estimating their actual BGL (Cox et al., 1991, 2001), and that error was common. Likewise, in the few cases that have been studied, estimates by diabetic adolescents and children also seemed to be imprecise, with only an average of between 30 and $40 \%$ accurate estimations (de la Fuente Arias \& Gil Roales-Nieto, 1994; GonderFrederick, Zinder, \& Clarke, 1991; Nurick \& Jonson, 1991).

During the past few decades, various research groups have continued investigate estimation management and have developed training procedures for estimating BGL. These procedures teach diabetic patients to correctly estimate their BGL by evaluating its variation with the maximum possible precision when it is impossible to obtain an objective reading via SMBG. For example, in the USA, Daniel Cox and his team of collaborators (Cox, Carter, GonderFrederick, Clarke, \& Pohl, 1988; Cox et al., 1991; Cox, Gonder-Frederick, Julian, \& Clarke, 1994; Cox et al., 2001) have developed training procedures primarily based on the use of internal cues from studies that indicated the highly idiosyncratic nature of symptoms specific to hyperglycemia as well as hypoglycemia (Cox, Gonder-Frederick, Antoun, Cryer, \& Clarke, 1993; Freund, Johnson, Rosenbloom, Alexander, \& Hansen, 1986; Gonder-Frederick, Cox, Bobbitt, \& Pennebaker, 1986).

Moreover, a detailed analysis of the idiosyncratic pattern of symptoms shown by patients has increased the customary presence of false beliefs about symptom-blood glucose relationships and the occurrence of misperceptions of symptoms contingent with extreme BGL. Thus, many patients may focus on symptoms that are actually false signals while ignoring others that truly indicate variations in BGL and can involve serious clinical consequences (Diamond, Massey, \& Covey, 1989; Gil Roales-Nieto \& Vílchez Joya, 1993; Gonder-Frederick et al., 1986). Similar findings have also been reported in diabetic children and adolescents (Freund et al., 1986; Wiebe, Alderfer, Palmer, Lindsay, \& Jarrett, 1994).

Other studies carried out in Spain, USA, and Chile by Gil Roales-Nieto and his collaborators, have led to the development of training procedures that include the preferred use of external cues (de la Fuente Arias \& Gil Roales-Nieto, 1994; Gil Roales-Nieto, 1998, 1991a; Luzoro \& Gil Roales-Nieto, 1993), taking into consideration those circumstances which produce BGL variations and whose occurrence or effects are perceivable or sensitive to recognition by the patient (Gil Roales-Nieto, 1998; Gil Roales-Nieto \& Vílchez Joya, 1993; Korn \& Matos, 2001). Actually, in two studies carried out with diabetic adolescents, the employment of these kinds of cues showed higher efficiency in BGL assessment as compared to relying on internal cues. The results of the first study showed that external cue training, using glycemic outlines as a temporary training standard, is effective in increasing the accuracy of patients' estimations, as well as in secondary improvement of various metabolic control ratings (Luzoro \& Gil RoalesNieto, 1993). In the second of these studies, the authors compared external cue training with other procedures such as feedback or internal cue training. Results indicated the superiority of external cue training (de la Fuente Arias \& Gil Roales-Nieto, 1994).

If blood glucose (BG) awareness training is an important part of a diabetics' education, it is even more important in the case of adolescent and pre-adolescent patients, as diabetic control in these kinds of patients involves special age-related complications.

On the other hand, before reaching adolescence, children are less likely to present problems such as physiological resistance to insulin or the negativity and typical adolescent rebellion that can often complicate this kind of intervention (Bryden et al., 2001; Dunger, 1992; Guthrie, Bartsocas, Jarosz-Chabot \& Konstantinova, 2003). However, very few studies have been carried out on the estimation management of diabetic children during preadolescence (Freund et al., 1986; Wiebe et al., 1994), which could provide keys for the adaptation of BG awareness training procedures to this group of patients. Furthermore, the few studies that were carried out fail to analyze which kinds of internal and/or external cues subjects really use when estimating their BGL.

The aims of this study include the analysis of accuracy in BGL estimation in pre-adolescent diabetic children with Type 1 diabetes, and the determination of the type of cues these children use to make their estimations. A third goal is the evaluation of the possible relationships between symptoms and extreme BGL in diabetic children. 


\section{Method}

\section{Participants}

Forty two children participated in this study (22 girls and 20 boys), aged between 9 and 14 years ( $M=11.3, S D$ $=1.8$ ), and diagnosed with Type 1 diabetes with a duration ranging from 1 to 12 years $(M=5.3, S D=3.2)$. Participants were selected from children attending two summer camps for diabetic children. In both camps, there were four established daily BG controls, one before each main meal (breakfast, lunch, and dinner) and before going to bed. In addition, children could request a BG analysis from the counselors if they suspected they were experiencing levels of hypo or hyperglycemia.

\section{Instruments}

The following instruments were used during this study:

The SI/IC-3 Symptom Scale, based on 22 symptoms and 6 feelings, selected from previous investigations developed by Gil Roales-Nieto (1993) and employed in the aforementioned studies, which groups symptoms normally associated with states of hypo- and hyperglycemia and is used to evaluate symptoms of perceived feelings and their intensity, on a 3-point rating scale ( $1=$ slight, 2 $=$ moderate, $3=a$ lot ). It also requires an exact $\mathrm{BGL}$ reading, first in general and subsequently with an exact number, allowing subjects to express their reasons for the estimations given.

Paper to collect spontaneous requests for SMBG, on which the time of the test was noted, as well as the patient's BGL estimation and the perceived symptoms at the time of the request, indicating intensity.

Glucometers (Esprit, Bayer Laboratories) and their corresponding reactive strips to obtain actual BGL from capillary samples. BGL was measured using milligrams of glucose per deciliter of blood, a measurement known and used by all diabetic patients and the measurement in which glucometers provide their results. Thus, subjects estimated their BGL with this measurement, while classifying it as high (hyperglycemia), low (hypoglycemia), or normal (euglycemia). The estimated BGL, as well as the actual levels obtained by the controls, were classified either as hypoglycemia $(<80 \mathrm{mg} / \mathrm{dl})$, euglycemia $(80-180 \mathrm{mg} / \mathrm{dl})$, or hyperglycemia (> $180 \mathrm{mg} / \mathrm{dl}$ ).

To gauge BGL estimation management, and in order to assess the adaptive value of the patients' estimation for diabetic control, the estimations were categorized as:

1. Clinically precise or correct: those estimation trials which revealed clinical correspondence between the patient's estimated BGL and the actual BGL (e.g., the participant reported suffering from hypoglycemia and the actual BGL indicate that this is true). Correct estimates include correctly perceiving hypoglycemia, hyperglycemia, and euglycemia.
2. Clinically imprecise or erroneous: those estimation trials which revealed a lack of such correspondence (e.g., the patient reports suffering from hypoglycemia and the actual BGL is normal). Two types of errors can be made according to guidelines established by Gil Roales-Nieto (1988, 1993): (a) false hypoglycemia and false hyperglycemia (e.g., when hypoglycemia is not present and patients estimate their BGL as hypoglycemic) and (b) actual hypoglycemia or unperceived hyperglycemia (e.g., when patients estimate their BGL as normal and they are actually hyperglycemic). A third type of error we will call inverse estimation is a combination of the previous two and implies an estimation contrary to the actual BGL (e.g., an estimation of hypoglycemia when the actual BGL indicates hyperglycemia and vice versa). This can lead to making a decision with dire consequences, as the patient might self-correct the estimated BGL, heading in the opposite direction of the treatment that is actually necessary, given the actual BGL.

An important aspect when analyzing estimation management and its errors is to determine which information patients use to make their estimations. In order to distinguish between the two main possibilities and to organize the analysis, when patients report having based their estimations on the perception of a symptom or on "how they feel," we will say that the patients were using "internal cues" (i.e., answers such as "because I was hungry," "because I was tired," "because I didn't feel anything," etc.). When individuals report having based their estimations on diet, exercise performed, administered insulin, or previous BGL, we will say that they were using "external cues."

\section{Procedure}

Starting on the second day of their stay and during the following days at camp, participants completed the SI/IC3 scale before each routine analysis (before breakfast, lunch and dinner). They did not complete the scale before going to bed for several reasons, such as they were tired, the general difficulty of filling in the scale, etc. In addition, when a child requested a BG analysis from a counselor, a form was filled out, stating the time of the analysis, the child's BGL estimation, and chief symptoms perceived, also indicating their intensity. An estimation trial was considered complete whenever participants completed the scale and their actual BGL was obtained, whether it was within the daily routine trials or in trials that were requested voluntarily. In each estimation trial, the following steps were taken:

1. Completion of the symptoms scale for the presence or absence of each cue along with its intensity in the former case.

2. Estimation of the BGL range (choosing between 3 options: hyperglycemic, hypoglycemic, or normal.)

3. Making a tangible estimation, indicating the exact BGL.

4. Giving all the reasons for arriving at their estimations.

5. Performing a BG analysis using a glucometer and noting the result. 


\section{Results}

During the study, a total of 959 estimation trials were completed by the participants with an average of 23 trials per individual $(S D=4)$, ranging between 16 and 32 trials. We evaluated the accuracy in estimating BGL for each participant using two results: (a) the error in estimation, obtained as the average of the differences in absolute value between the actual BGL and the estimation given in each trial; and (b) the correlation between estimated and actual BGL. Results are shown in Table 1.

The average value of the correlations between estimated BGL values and actual BGL is moderate $(r=.41)$, and the data range (-.21 to .84$)$ shows the large individual differences observed when estimating BGL. For example, although 18 individuals had statistically significant correlations, which would indicate an acceptable level of accuracy in the estimation, another 5 participants had negative correlations, revealing a very low capacity for performing correct estimations. The average estimation error also showed a moderately high BG level $(63.8 \mathrm{mg} / \mathrm{dl})$ and a broad range (26.8 to $120.9 \mathrm{mg} / \mathrm{dl}$ ), which confirms what the correlations between estimated and actual BGL indicated. Keep in mind that an estimation error greater than 20 or $30 \mathrm{mg} / \mathrm{dl}$ would be considered a potentially dangerous error in diabetic control, especially when the actual BGL is bordering on normal levels.

As far as the quality of the estimation, which can also be seen in Table 1, participants showed a greater percentage of precision than errors, $57.7 \%$ versus $43.4 \%, t=3.564, p=$ .001). Among the errors committed, participants showed a greater percentage of undetected episodes than false estimations, $23.8 \%$ versus $14.7 \%, t=3.104, p<.01$, and among the undetected episodes, more were hyperglycemic than hypoglycemic, $16.3 \%$ versus $7.5 \%, t)=-4.014, p<.001$. There were, however, no significant differences observed between the estimations of false hypoglycemia and false hyperglycemia, or between the two types of possible inversions (estimated hypoglycemia with actual hyperglycemia and estimated hyperglycemia with actual hypoglycemia).

We evaluated the possible relationships of various participant characteristics such as age, duration of diabetes, average real BGL values, and BGL variability with the precision for estimating BGL, more specifically, with the average estimation error using $t$ tests. Using the averages of the sample, we created contrast groups for age (average 11 years), duration of diabetes (average 4.5 years), average BGL value $(165.8 \mathrm{mg} / \mathrm{dl})$, and BGL variability (average 84.3 $\mathrm{mg} / \mathrm{dl}$ ). We found a statistically significant relationship with average BGL values, 51.7 versus $74.7 \mathrm{mg} / \mathrm{dl}, t=-4.14, p<$ .01 , and with BGL variability, $54.7 \mathrm{mg} / \mathrm{dl}$ versus $72.8 \mathrm{mg} / \mathrm{dl}$, $t=-3.01, p<.01$, but not with age or duration of illness.

In order to analyze estimation management and its errors, we used the information provided by the participants about on what they based their estimations, distinguishing between the use of internal and external cues. In Table 2, we present the average percentage of estimation trials in which participants used internal cues, external cues, or a combination of both. The results indicate greater usage of internal cues compared to external cues or a combination of both, $F=$ $120.99, p<.001$.

Table 1

Means, Range and Standard Deviations of Accuracy of BGL Estimations

\begin{tabular}{lccr}
\hline & Mean & Range & \multicolumn{1}{c}{$S D$} \\
\hline Estimation error (in mg/dl) & 63.8 & $26.8-120.9$ & 21.25 \\
Correlation estimated/actual BGL & .41 & $-.21-.84$ & .26 \\
Correct trials (\%) & $57.7 \%$ & $23.6-88.7$ & 13.82 \\
$\quad$ Detected Hypoglycemia & $16.3 \%$ & $0-50$ & 11.67 \\
$\quad$ Detected Hyperglycemia & $17.0 \%$ & $0-71.4$ & 16.12 \\
$\quad$ Detected Euglycemia & $24.3 \%$ & $0-68.4$ & 16.49 \\
Erroneous trials (\%) & $43.4 \%$ & $15-76.2$ & 12.48 \\
$\quad$ Hypo and Hyperglycemia & $23.9 \%$ & $9.1-56.2$ & 11.09 \\
$\quad$ Undetected & & & \\
$\quad$ False Hypo- and Hyperglycemia & $14.7 \%$ & $0-44.4$ & 6.21 \\
$\quad$ Inverse estimations & $4.8 \%$ & $0-28.6$ & \\
\hline
\end{tabular}

Table 2

Percentage of Trials Using Internal and/or External Cues

\begin{tabular}{lccc}
\hline & Mean & Range & $S D$ \\
\hline Use of external cues (\% of trials) & 17.7 & $0-81$ & 22.2 \\
Use of internal cues (\% of trials) & 70.7 & $0-100$ & 29.1 \\
Use of internal and external cues (\% of trials) & 1.7 & $0-25$ & 4.3 \\
\hline
\end{tabular}


In the attempt to precisely assess estimation management, we analyzed the internal or external cues indicated by participants in the estimation trials as qualifying as correct as well as erroneous, calculating the percentage of individuals who indicated each cue in at least one trial.

In the first case, correct estimations, regarding correctly perceived hypoglycemia (see Figure 1), participants more frequently used [internal] symptom cues such as feeling dizzy $(61.1 \%)$ or trembling $(27.8 \%)$, as well as various combinations of two or more cues $(38.9 \%)$ such as feeling dizzy and trembling, feeling dizzy and tired, feeling dizzy and having blurry vision, etc. Other less frequently reported symptoms were feeling hungry, nervous, tired, having a stomach ache, and headache. As can be seen in Figure 2, in the trials where hyperglycemia was correctly perceived, the opposite occurred: participants primarily used external cues such as the values of previous BGL trials $(31.2 \%)$, diet $(18.7 \%)$, physical exercise $(15.6 \%)$, insulin $(12.5 \%)$, or a combination of these $(15.6 \%)$, and less frequently, they used internal cues such as drowsiness $(15.6 \%)$, dry mouth $(9.3 \%)$, or a combination of two or more cues $(15.6 \%)$ such as thirst and dry mouth, drowsiness and dry mouth, etc. Regarding correct euglycemia estimations (see Figure 3), the results showed that participants based their estimations on general judgments such as "feeling well" $(71.1 \%)$, or the absence of symptoms or sensations $(42.1 \%)$, and, to a lesser degree, on the use of external cues such as values of previous BGL trials (15.8\%), diet (13.2\%), physical exercise $(10.5 \%)$, or a combination of these $(18.4 \%)$.

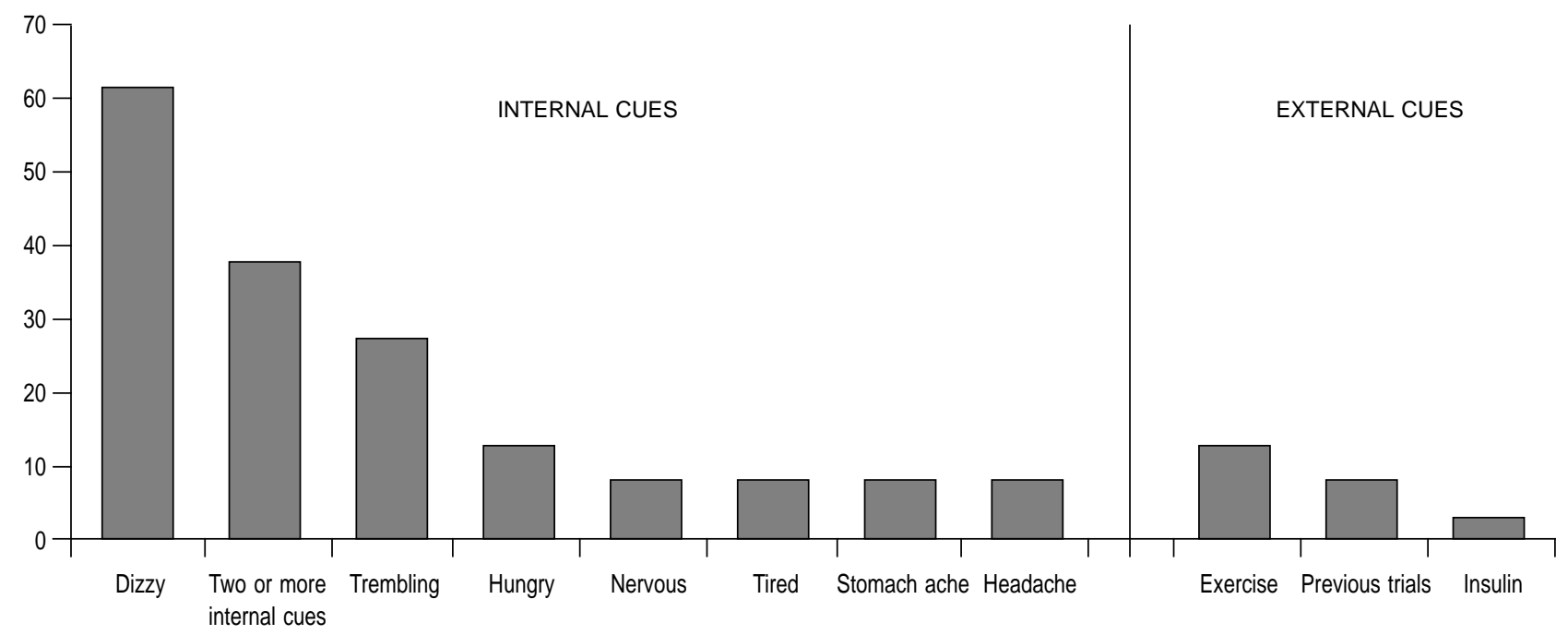

Figure 1. Percentage of participants who used each cue (internal or external) in perceived hypoglycemia trials.

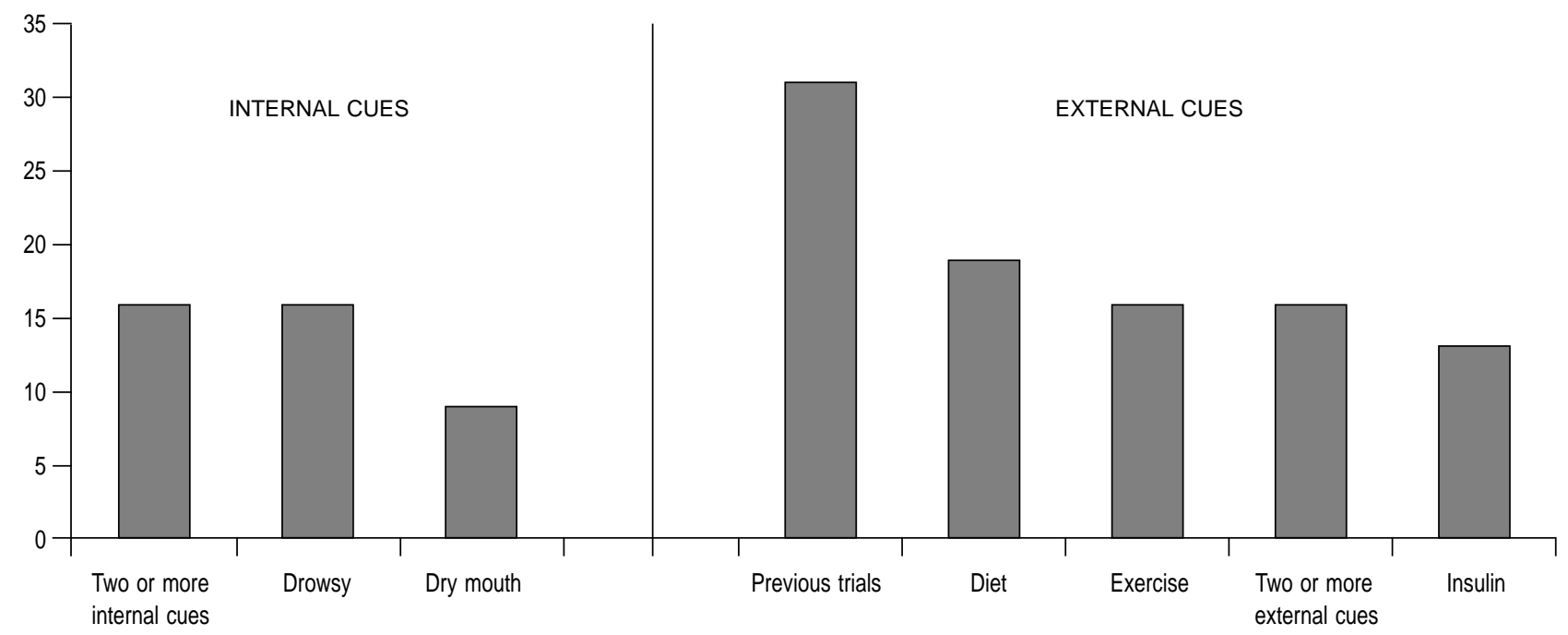

Figure 2. Percentage of participants who used each cue (internal or external) in perceived hyperglycemia trials. 


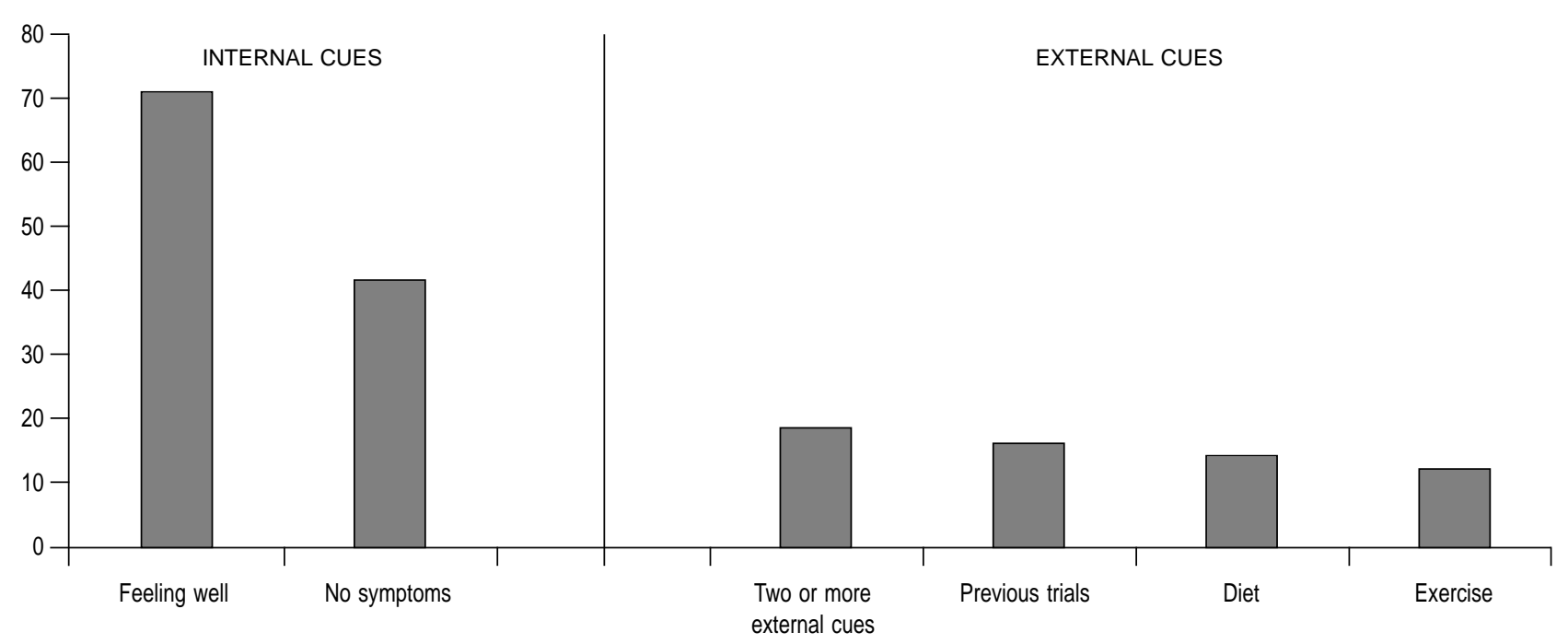

Figure 3. Percentage of participants who used each cue (internal or external) in perceived euglycemia trials.

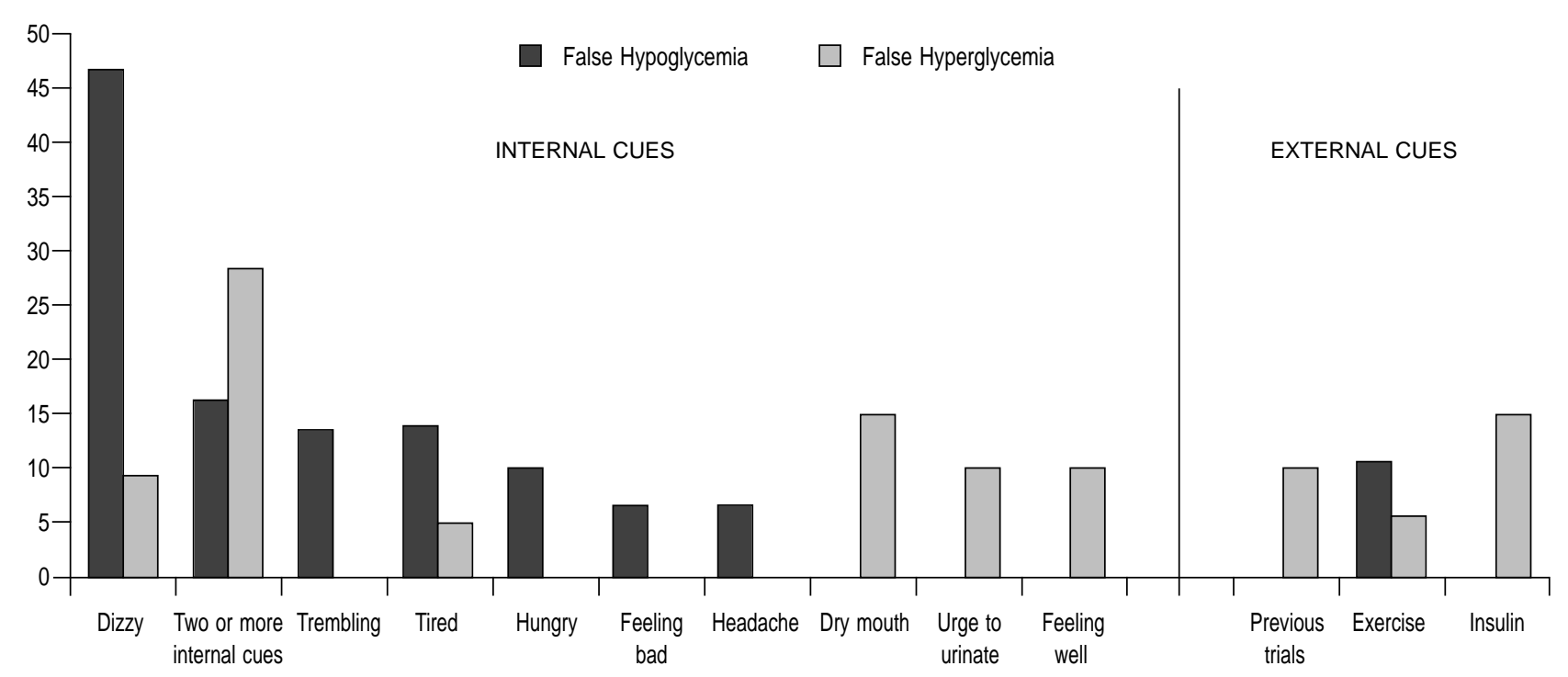

Figure 4. Percentage of participants who used each cue (internal or external) in false hypo- and hyperglycemia trials.

In trials qualifying estimations as imprecise or erroneous, the results with regard to false hypo- or hyperglycemia estimations (see Figure 4) showed that participants preferred to use symptoms or internal cues such as feeling dizzy (46.7\%), trembling $(13.3 \%)$, or feeling tired $(13.3 \%)$ in the cases resulting in false hypoglycemia. Cues such as dry mouth $(14.3 \%)$ or a combination with others such as drowsiness, bad taste in the mouth, or urge to urinate (28.6\%) were the most common in the trials that resulted in false hyperglycemia estimations. In a few cases, the use of external cues resulted in an estimation of false hypoglycemia and false hyperglycemia except, in the latter case, when administered insulin was used as a cue $(14.3 \%)$.
Regarding the other kinds of errors in estimations, in the cases of actual hypoglycemia and hyperglycemia that were unperceived (see Figure 5), the majority of the participants indicated having used general sensations such as "feeling well" or "not feeling anything" or the absence of typical symptoms related to hypo- and hyperglycemia. In these cases, we observed greater use of external cues with respect to false alarms.

Lastly, in the estimation trials which resulted in an inverse estimation regarding the actual BGL value (see Figure 6), we observed a large difference between the two possible cases, given that, whereas, in the case of estimated hypoglycemia with actual hyperglycemia, the most commonly used cue was feeling dizzy $(56.2 \%)$ and, in the 


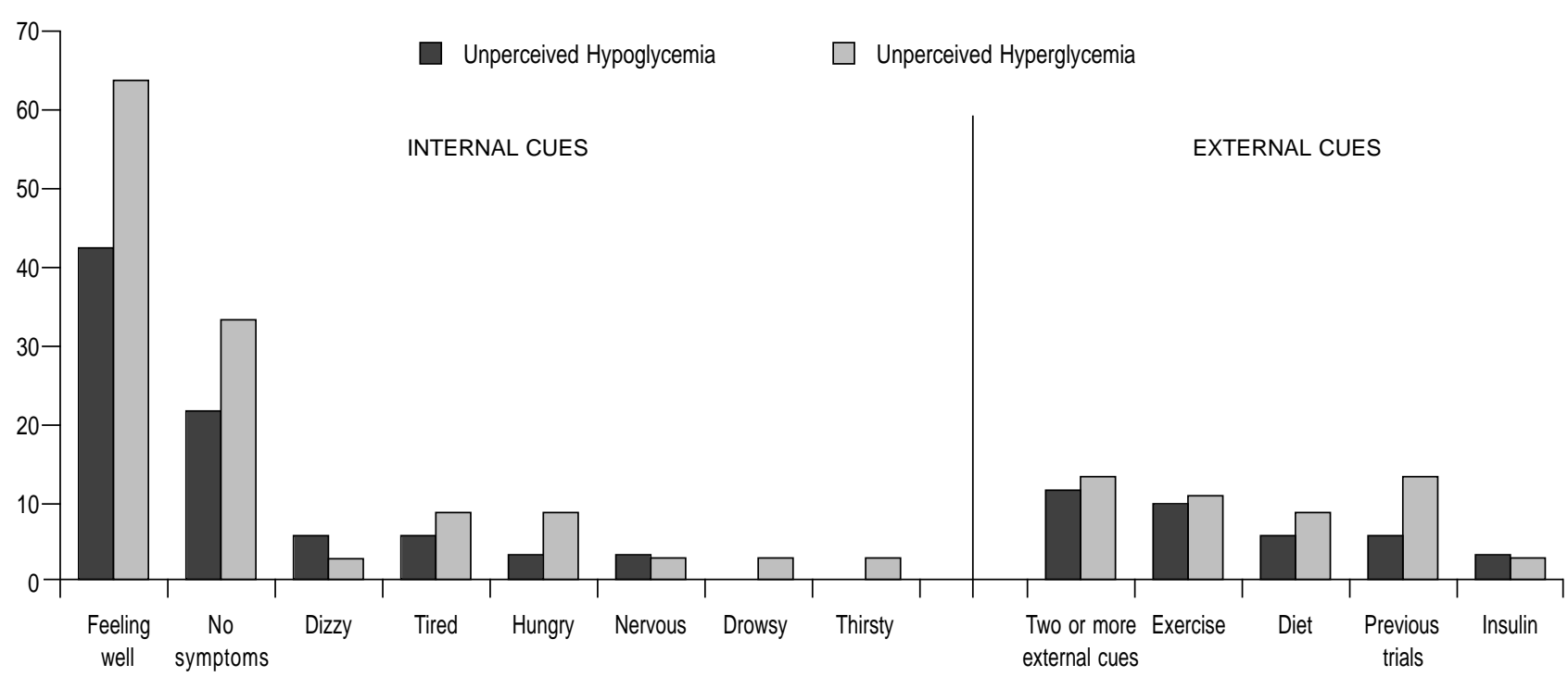

Figure 5. Percentage of participants who used each cue (internal or external) in unperceived hyper- or hypoglycemia trials.

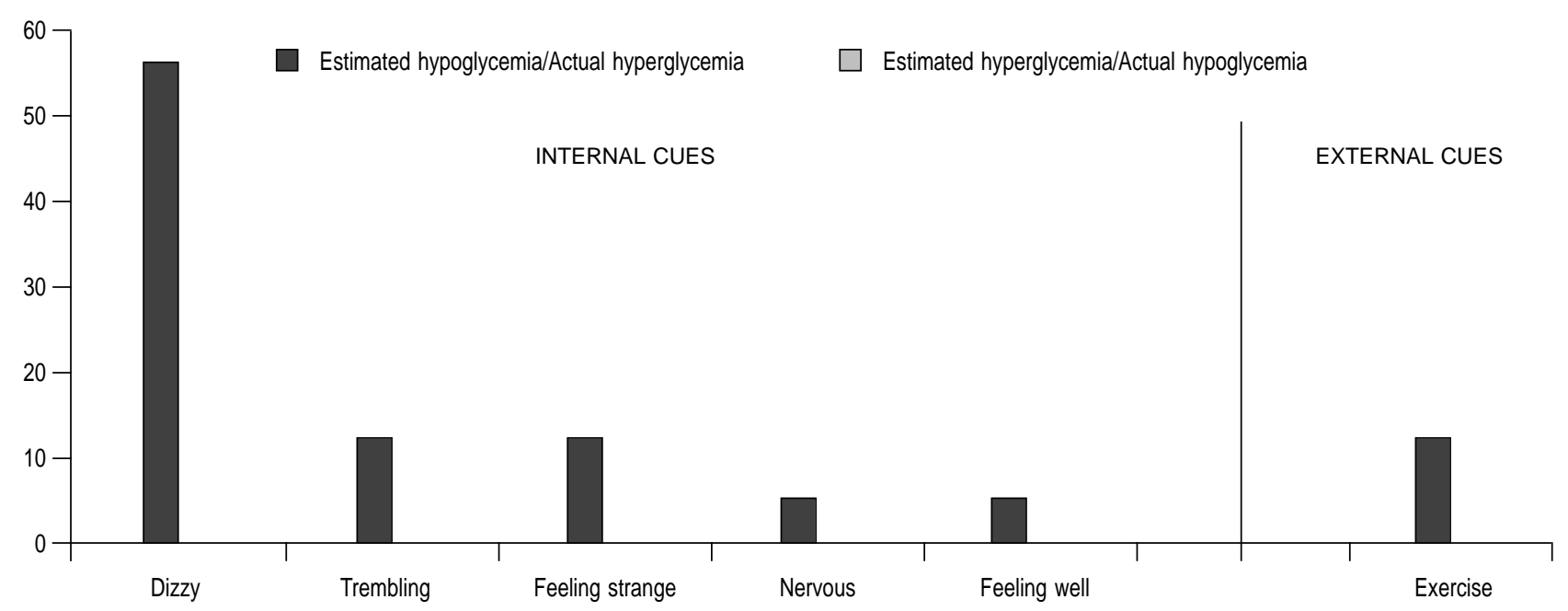

Figure 6. Percentage of participants who used each cue (internal or external) in inverse estimation trials.

case of estimated hyperglycemia with actual hypoglycemia, lack of exercise $(27.3 \%)$ was the most common cue.

Regarding the procedure used in this study, for ethical reasons, we were aware of the actual BGL immediately following each analysis. This raised the possibility that it could be used as feedback, which would allow an improvement in estimation accuracy. To determine whether this effect occurred, we performed a repeated measures analysis of variance, comparing estimation accuracy at different periods (the beginning, middle, and end of the study), and used the errors in estimation as a dependant variable. The results showed no significant differences in the accuracy of estimations throughout these periods, $F=$ $0.004, p>.05$.
Lastly, to determine the number of BGL-related symptoms in each participant, we calculated Spearman's intra-subject correlations between each symptom and the actual BGL data obtained. Thus, for each individual, we calculated a total of 28 correlations, at a significance level of $p<.05$. In order to increase the validity of the symptom data, correlations were calculated between the intensity levels reported for each symptom in the different trials and the actual BGL value obtained on each occasion.

As pointed out by Gonder-Frederick, Cox, Bobbitt and Pennebaker (1989), at the time these correlations were obtained, BGL values could be treated either as categorical variables (e.g., low, normal, or high levels, equivalent to the ranges of hypoglycemia, euglycemia, and hyperglycemia, 
respectively) or as continuous variables. As previous studies have shown that the patterns of symptoms obtained with both methods are practically identical (Gonder-Frederick et al., 1986; Pennebaker et al., 1981), we decided to treat the BGL values as continuous variables, following the example of Gonder-Frederick et al. (1989). After examining the results, a relationship between a symptom and a certain BGL was noted if their correlation was statistically significant. A positive correlation coefficient indicates that a symptom is related to hyperglycemic BGL, whereas a negative correlation coefficient indicates that a symptom is related to hypoglycemic BGL (Gonder-Frederick et al., 1989; Pennebaker et al., 1981).

The total of all BGL values of all participants was within a range of $30 \mathrm{mg} / \mathrm{dl}$ to $574 \mathrm{mg} / \mathrm{dl}(M=165.5 \mathrm{mg} / \mathrm{dl} ; S D=$ 94.5). The frequency distribution showed that $207 \%$ of the BGLs were hypoglycemic $(<80 \mathrm{mg} / \mathrm{dl}), 40.6 \%$ were euglycemic (80-180 mg/dl), and $38.7 \%$ were hyperglycemic (> $180 \mathrm{mg} / \mathrm{dl}$ ). One individual neither presented a hyperglycemic BGL nor showed a positive correlation coefficient, which indicates the existence of predictive symptoms of high BGL. In addition, two individuals neither presented hypoglycemic BGL nor did they have negative correlation coefficients, which indicates the existence of predictive symptoms of low BGL.

The results of the intra-subject correlations analysis showed that only for four persons, the correlations between symptoms and BGL were nonsignificant, and for 18 participants, there was only a significant correlation for one symptom. Thirteen participants presented significant correlations with hypoglycemic as well as hyperglycemic BGLs, 12 with hyperglycemic BGL only, and 13 with hypoglycemic BGL only. Taking all the participants into account, we found a greater number of correlations with hyperglycemic BGL than with hypoglycemic BGL (53 vs. 33). For each item on the scale, we calculated the percentage of individuals for which a symptom correlated with a low or high BGL. The results are shown in Table 3. The symptom that correlated the most frequently in persons with low BGL

Table 3

Percentage of Participants for Whom each Symptom was Significantly Related to BGL

\begin{tabular}{lccc}
\hline Perceived symptom & Low BGL & High BGL & Total \\
\hline Headache & 4.8 & 9.5 & 14.3 \\
Feeling tired/ weak & 2.4 & 7.1 & 9.5 \\
Stomach ache or discomfort & 2.4 & 11.9 & 14.3 \\
Feeling sluggish or lazy & 4.8 & 4.8 & 9.6 \\
Feeling dizzy & 26.2 & 0 & 26.2 \\
Bad taste in the mouth & 2.4 & 0 & 2.4 \\
Awake and full of energy & 2.4 & 7.1 & 9.5 \\
Dry mouth & 0 & 7.1 & 7.1 \\
Feeling relaxed & 0 & 4.8 & 4.8 \\
Feeling nervous & 4.8 & 2.4 & 7.2 \\
Feeling thirsty & 0 & 16.6 & 16.6 \\
Feeling worried & 0 & 4.8 & 4.8 \\
Trembling & 9.5 & 0 & 9.5 \\
Rapid heartbeat & 0 & 0 & 0 \\
Feeling sad & 2.4 & 4.8 & 7.2 \\
Blurry vision & 2.4 & 0 & 2.4 \\
Difficulty speaking & 0 & 0 & 0 \\
Feeling happy & 0 & 9.5 & 9.5 \\
Feeling flushed & 2.4 & 2.4 & 4.8 \\
Sweating & 2.4 & 0 & 2.4 \\
Urge to urinate & 0 & 2.4 & 2.4 \\
Feeling hungry & 0 & 7.1 & 7.1 \\
Salivation & 0 & 2.4 & 2.4 \\
Feeling sure and confident & 0 & 2.4 & 2.4 \\
Difficulty concentrating & 0 & 2.4 & 2.4 \\
Difficulty breathing & 0 & 00 & 4.8 \\
Feeling angry & 0 & 4.8 & 2.4 \\
Feeling drowsy & 4.8 & 14.3 & 0 \\
Feeling bad & 2.4 & 0 & \\
Feeling empty & 2.4 & & 2.4 \\
\hline
\end{tabular}


values was "feeling dizzy" ( $26.2 \%$ of the participants). Other symptoms that stood out were "feeling thirsty," which correlated with high BGL in $16.7 \%$ of the participants, and "feeling drowsy," which correlated with high BGL in 14.3\% of the sample, as well as with low BGL in $4.8 \%$.

\section{Discussion}

The results showed great variability in the capacity of diabetic pre-adolescents to estimate their BGL. Some patients showed acceptable accuracy in estimation, and some patients showed very poor ability to estimate, similar to the results obtained by Freund et al. (1986) with a sample of diabetic adolescents.

The analysis of the estimations carried out indicates that the participants showed a high number of BGL-estimation errors (in fact, an average of $43.36 \%$ of the trials was erroneous or clinically imprecise). Similarly, a greater number of trials resulted in unperceived actual hypoglycemia or hyperglycemia, as opposed to the trials in which the estimation was a false hypo- or hyperglycemia. In addition, and of great importance to diabetic care, a large number of trials resulted in an inverse estimation, which represents the severe risk of a patient taking management steps contrary to those that should be taken, considering the actual BGL at that time.

There are a variety of possible explanations for the elevated number of errors in unperceived hypo- and hyperglycemia. One of these is to consider that the basic error lies in the perception and recognition of the symptoms that accompany these conditions, although this explanation must be emphasized for those errors in unperceived hyperglycemia when the actual BGL values are not extreme, as moderate hyperglycemia frequently occurs with no symptoms. On the other hand, an alternative explanation has to do with the tendency found in diabetic patients to "normalize their BGL" when reporting it; that is, the estimation of their BGLs as normal or close to normal would prevent them from recognizing hypo- and hyperglycemia by not adequately appraising the symptoms and/or external cues (Gil Roales-Nieto, 2000b), which is an obstacle to a correct estimation.

The type of cue used by individuals to make correct estimations is a relevant result for diabetic self-monitoring because this can indicate guidelines that should be emphasized in programs for diabetic intervention. Especially relevant is the frequent use of internal cues in the estimation trials (in almost $71 \%$ of the trials, we observed the use of this kind of cue), which emphasizes the need for accuracy training when using a type of cue that is difficult to dismiss for people who are sensitive to perceivable changes within themselves. Upon analyzing the cues used in the trials with correct estimations, we observed that, when correctly estimating hypoglycemia, participants based their judgments primarily on internal cues, whereas correctly estimated hyperglycemia was largely based on external cues. This may reflect sensitivity to neuroglucopenic and/or adrenergic symptoms produced during hypoglycemic episodes and indicate the need to use external cues during hyperglycemia that occurs asymptomatically. In the case of correct euglycemia estimations, the individuals based their judgments on the absence of symptoms or discomfort as well as on external cues, which underscores the importance of the latter as key s to diabetic self-management.

When focusing on the analysis of erroneous estimations, we observe that, in the case of false hypoglycemia, participants used internal cues or similar symptoms to those used in correct hypoglycemia estimations, which could indicate a generalization effect in the control of these symptoms and make their functional discrimination more difficult. Thus, a child who "feels dizzy" could blame it on a hypoglycemic episode when, in fact, no such episode is actually present. The child could be responding erroneously to a symptom that could have been produced by something other than a decrease in BGL.

These cases of incorrect estimations are impossible to resolve if one only considers symptoms and not those external cues that would indicate the slight probability of a hypoglycemic episode (for example, being aware that a recent meal, the absence of intense exercise, and the insulin available in the blood would not signal that hypoglycemia is developing). To be guided exclusively by symptoms can cause errors in over-correction and weaken the correct discriminative function of the symptom.

Another interesting result, which confirms the previous analyses, is the fact that in the false hyperglycemia estimations, we observed a greater use of internal cues when compared to the estimations of correctly perceived hyperglycemia. This indicates the probable presence of false beliefs about symptoms that require special attention. Lastly, regarding actual unperceived hypo- and hyperglycemia, the data indicate that these errors occur when the individual relates the absence of symptoms to normal BGL, another false belief that is difficult to detect and is usually undetected in psychological work with diabetic patients.

Regarding relationships between symptoms and extreme BGL, the data indicate great differences between subjects, in accordance with results from previous studies (Cox, Gonder-Frederick, Pohl, \& Pennebaker, 1983; Cox, GonderFrederick, Antoun, Cryer, \& Clarke, 1993; Freund et al., 1986) that have noted this peculiarity. However, certain symptoms seem to be more common than others, such as "feeling dizzy," which was related to low BGL in $26.4 \%$ of the participants, or "being thirsty," which was related to high BGL in $16.7 \%$ of the individuals. These results do not correspond to those obtained in other studies, such as that by Freund et al. (1986). Another interesting finding is the higher total number of relationships between symptoms and high BGL than between symptoms and low BGL. This could be due to the fact that the participants maintained high BGL 
during the study. This would facilitate the appearance of more relationships between the symptoms and high BGL. However, there are alternative explanations, the limitations of which require considering the exact BGL to determine whether just severe hyperglycemia would, by itself, explain this phenomenon or whether other variables should be considered. In sum, the results of this study show that the majority of children, aged 9 to 14 years, with Type 1 diabetes present adrenergic and neuroglucopenic symptoms associated with episodes of hypoglycemia and that they are sensitive to these symptoms, appraising them as warning signals. However, numerous aspects of BGL estimation management show deficiencies that can affect diabetic self-management, as estimation errors are frequent and some of them could have severe consequences. This shows that intervention, in the form of BGL-discrimination training programs, is an essential goal in diabetic care. Likewise, the results show that the different functions performed by symptoms, internal, and external cues, and their correct combination, is necessary for an accurate BGL estimation at times when it is not possible to perform an analysis.

\section{References}

Beléndez, M., Ros, M.C. \& Bermejo, R. M. (1999). Diabetes infantil: Guía para padres, educadores y adolescents. Madrid: Ediciones Pirámide.

Bryden, K.S., Peveler, R.C., Stein, A., Neil, A., Mayou, R.A., \& Dunger, D.B. (2001). Clinical and psychological course of diabetes from adolescence to young adulthood: A longitudinal cohort study. Diabetes Care, 24, 1536-1540.

Cox, D.J., Carter, W.R., Gonder-Frederick, L., Clarke, W.L., \& Pohl, S.L. (1988). Blood glucose discrimination training in insulin-dependent diabetes mellitus (IDDM) patients. Biofeedback Self Regulation, 13, 201-217.

Cox, D.J., Gonder-Frederick, L., Antoun, B., Cryer, P.E. \& Clarke, W.L. (1993). Perceived symptoms in the recognition of hypoglycemia. Diabetes Care, 16, 519-527.

Cox, D. J., Gonder-Frederick, L., Julian, D.M., \& Clarke, W. (1994). Long-term follow-up evaluation of blood glucose awareness training. Diabetes Care, 17, 1-5.

Cox, D.J., Gonder-Frederick, L., Julian, D.M., Cryer, P. E., Lee, J.H., Richard, S.E., \& Clarke, W.L. (1991). Intensive versus standard blood glucose awareness training (BGAT) with insulindependent diabetes: Mechanisms and ancillary effects. Psychosomatic Medicine, 53, 453-462.

Cox, D.J., Gonder-Frederick, L., Pohl, S., \& Pennebaker, J.W. (1983). Reliability of symptom-blood glucose relationships among insulin-dependent adult diabetics. Psychosomatic Medicine, 45, 357-360.

Cox, D.J., Gonder-Frederick, L., Polonsky, W., Schlundt, D., Kovatchev, B., \& Clarke, W. (2001). Blood glucose awareness training (BGAT-2): Long-term benefits. Diabetes Care, 24, 637-642. de la Fuente Arias, M., \& Gil Roales-Nieto, J. (1994). Entrenamiento en discriminación de niveles de glucosa en sangre: estudio comparativo. Revista de Psicología de la Salud, 6, 35-57.

Diamond, E.L., Massey, K.L., \& Covey, D. (1989). Symptom awareness and blood glucose estimation in diabetic adults. Health Psychology, 8, 15-26.

Dunger, D.B. (1992). Diabetes in puberty. Archives of Disease in Childhood, 67, 569-570.

Freund, A., Johnson, S.B., Rosenbloom, A., Alexander, B., \& Hansen, C.A. (1986). Subjective symptoms, blood glucose estimation, and blood glucose concentrations in adolescents with diabetes. Diabetes Care, 9, 236-243.

Gil Roales-Nieto, J. (1988). Blood glucose discrimination in insulindependent diabetics. Training in feedback and external cues. Behavior Modification, 12, 116-132.

Gil Roales-Nieto, J. (1991a). Entrenamiento de feedback y señales externas en discriminación de niveles de glucosa en sangre en diabéticos insulinodependientes. Analisis y Modificación de Conducta, 17, 951-965.

Gil Roales-Nieto, J. (1991b). Intervención conductual en diabetes mellitus: procedimientos de discriminación de niveles de glucosa en sangre. In J. Gil Roales-Nieto \& T. Ayllon (Eds.), Medicina Conductual 1: Intervenciones conductuales en problemas médicos y de salud (pp. 101-144). Granada: Servicio de Publicaciones de la Universidad de Granada.

Gil Roales-Nieto, J. (2000a). Discriminación del riesgo como comportamiento de riesgo. In J. Gil Roales-Nieto (Ed.), Manual de Psicología de la Salud, Vol. 2. Comportamiento y salud/enfermedad (pp. 23-51). Granada, Spain: Némesis.

Gil Roales-Nieto, J. (2000b). Manual de Psicología de la Salud, Vol. 2. Comportamiento y salud/enfermedad. Granada: Némesis.

Gil Roales-Nieto, J. (2004). Psicología de la Salud. Aproximación histórica, conceptual y aplicaciones. Madrid: Ediciones Pirámide.

Gil Roales-Nieto, J., \& Vílchez Joya, R. (1993). Diabetes. Intervención psicológica. Madrid: Eudema.

Gonder-Frederick, L., Cox, D.J., Bobbitt, S.A., \& Pennebaker, J.W. (1989). Mood changes associated with blood glucose fluctuations in insulin-dependent diabetes mellitus. Health Psychology, 8, 45-59.

Gonder-Frederick, L., Cox, D., \& Ritterband, L. (2002). Diabetes and behavioral medicine: The second decade. Journal of Consulting and Clinical Psychology, 70, 611-625.

Gonder-Frederick, L., Cox, D. J., Bobbitt, S.A., \& Pennebaker, J.W. (1986). Blood glucose symptom beliefs of diabetic patients: Accuracy and implications. Health Psychology, 5, 327-341.

Gonder-Frederick, L., Zinder, A.L., \& Clarke, W.L. (1991). Accuracy of blood glucose estimation by children with IDDM and their parents. Diabetes Care, 14, 565-570.

Guthrie, D.W., Bartsocas, C., Jarosz-Chabot, P., \& Konstantinova, M. (2003). Psychosocial issues for children and adolescents with diabetes: Overview and recommendations. Diabetes Spectrum, 16, 7-12. 
Jones, P.M., Remley, C., \& Engberg, R.A. (1996). Development and testing of the Barriers to Self-Monitoring Blood Glucose Scale. Diabetes Educator, 22, 609-616.

Karter, A.J., Ferrara, A., Darbinian, J.A., Ackerson, L.M., \& Selby, J.V. (2000). Self-monitoring of blood glucose: Language and financial barriers in a managed care population with diabetes. Diabetes Care, 23, 477-483.

Luzoro, J., \& Gil Roales-Nieto, J. (1993). Discriminación de niveles de glucosa en sangre en diabéticos insulinodependientes mediante señales externas y perfiles glucémicos. Psicothema, 5, 45-65.

Nurick, M.A., \& Jonson, S B. (1991). Enhancing blood glucose awareness in adolescents and young adults with IDDM. Diabetes-Care, 14, 1-7.

Nyomba, B.L.G., Berard, L., \& Murphy, L.J. (2002). The cost of selfmonitoring of blood glucose is an important factor limiting glycemic control in diabetic patients. Diabetes Care, 25, 1244-1245.
Pennebaker, J.W., Cox, D.J., Gonder-Frederick, L., Wunsch, M.G., Evans, W.S., \& Pohl, S. (1981). Physical symptoms related to blood glucose in insulin-dependent diabetics. Psychosomatic Medicine, 43, 489-500.

Wiebe, D.J., Alderfer, M.A., Palmer, C.S., Lindsay, R., \& Jarrett, L. (1994). Behavioral self-regulation in adolescents with Type I diabetes: Negative affectivity and blood glucose symptom perception. Journal of Consulting and Clinical Psychology, 62, 1204-1212.

Zgibor, J.C., \& Simmons, D. (2002). Barriers to blood glucose monitoring in a multiethnic community. Diabetes Care, 25, 1772-1777.

Received May, 31, 2004 Revision received August, 2, 2004 Accepted September, 1, 2004 